\title{
Is the number of tree species in small tropical forest plots nonrandom?
}

\author{
M. W. Palmer ${ }^{1}$, D. B. Clark $^{2}$ and D. A. Clark $^{2}$ \\ ${ }^{1}$ Department of Botany, Oklahoma State University, Stillwater, Oklahoma, USA 74078. E-mail: \\ carex@osuunx.ucc.okstate.edu \\ ${ }^{2}$ University of Missouri-St. Louis, St. Louis, Missouri, USA, and La Selva Biological Station, Costa Rica.
}

Keywords: Costa Rica, Generalized linear models, La Selva Biological Station, Randomization test, Rarefaction effect, Species richness, Tropical rainforest.

\begin{abstract}
Tree species richness is remarkably high in many tropical forests, even at very fine spatial scales. However, the study of fine-scale richness is complicated by the rarefaction effect: that is, a trivial correlation between the number of individuals and the number of species. We developed null models to test whether fine-scale species richness differs from random expectation, and applied these models to a dataset of $1170100 \mathrm{~m}^{2}$ circular plots in the old-growth portion of La Selva Biological Station in the Atlantic Lowlands of Costa Rica. Although species richness in these plots was close to its theoretical maximum, we found that it was frequently lower than null expectation. This was a result of slightly clumped distributions within species. We found no relationships between species richness at the $100 \mathrm{~m}^{2}$ scale and soil type or topography, after accounting for the effects of density.
\end{abstract}

\section{Introduction}

The impressive biodiversity of tropical rainforest trees is well known to ecologists as well as the general public (Wilson 1998). Despite such attention, the causes of the high diversity remain elusive (Leigh 1999). Over the course of decades, researchers have proposed a copious array of hypotheses to explain patterns of species richness, or the number of species per unit area (reviewed in Gentry 1988, Huston 1994, Palmer 1994, Rosenzweig 1995, Leigh 1999). Some hypotheses explain high tropical diversity on a coarse scale; e.g., on the basis of biogeography, evolutionary history, species ranges, or the 'species pool' (Rohde 1997, Rosenzweig 1995, Stevens 1989). Other hypotheses, such as the pest pressure hypothesis (e.g., Janzen 1970), the niche diversification hypothesis (e.g., Connell 1978), explanations invoking mycorrhizae (Janos 1983), and explanations related to treefall gaps (e.g., Denslow 1995, Brokaw 1985) explain diversity on the basis of interspecific interactions or finescale interactions. Fine and coarse-scale hypotheses of diversity are not necessarily incompatible; indeed, it may be necessary to combine them to explain both the 'origin' as well as 'maintenance' of diversity (Brown 1988).

Any definitions of a particular 'scale' must be arbitrary (Palmer and White 1994a,b). However, for the present purposes, we define 'fine scale' as 0.01 ha, or the scale of a few mature trees. It is within this order of magnitude in size that we can expect canopies and rhizospheres to interact. If the scale is much larger (especially in such variegated landscapes as the one studied here), we can expect substantial variation in geomorphology, hydrology, and soils.

If diversity is indeed maintained at a fine scale, it is reasonable to suppose that sampling tropical forests at a fine scale should be adequate for revealing the mechanisms behind such maintenance. However, a number of investigators of tropical forests and other systems have pointed out that fine-scale diversities are complicated by the 'rarefaction effect' (Palmer 1991, Denslow 1995, Palmer and van der Maarel 1995, Hubbell et al. 1999, Pärtel and Zobel 1999). Here, we use the term 'rarefaction effect' to refer to cases where diversity effects are difficult 
Table 1. Numbers of $100 \mathrm{~m}^{2}$ plots in each soil and topographic class.

\begin{tabular}{|c|c|c|c|c|c|c|}
\hline & \multicolumn{5}{|c|}{ Soil Type } & \\
\hline Topographic Class & $\begin{array}{c}\text { Old } \\
\text { Alluvium }\end{array}$ & $\begin{array}{c}\text { Recent } \\
\text { Alluvium }\end{array}$ & Residual & $\begin{array}{l}\text { Stream } \\
\text { Valley }\end{array}$ & Swamp & Total \\
\hline Ridge Top / Flat & 60 & 16 & 23 & 12 & 69 & 180 \\
\hline Top of Slope & 25 & 1 & 205 & 3 & 0 & 234 \\
\hline Midslope & 51 & 7 & 472 & 14 & 3 & 547 \\
\hline Base of Slope/Riparian & 4 & 8 & 98 & 65 & 34 & 209 \\
\hline Total & 140 & 32 & 798 & 94 & 106 & 1170 \\
\hline
\end{tabular}

to disentangle from density effects; we prefer this specific term to the very general terms previously offered in the literature (e.g., 'sampling artifact', 'no-interaction model', 'density effect'). The rarefaction effect occurs because species cannot occur independently of individuals, and hence there is a built-in correlation between density and richness at low densities. Condit et al. (1996, 1998) argued that this problem is so extreme in tropical forests that at least 1000 trees should be sampled before species richness can be compared among sites. Although Condit et al. are comparing geographically isolated locations, their findings imply that there are severe constraints on our ability to understand fine-scale determinants of tree diversity.

Several authors have suggested ways to 'correct for' the rarefaction effect in tropical forest studies. For example, Denslow (1995) extrapolated the species-individual curve to infinite sampling using a Michaelis-Menten equation. Unfortunately, the abstraction of infinite stem density in small quadrats may be biologically untenable. An alternative approach presented by Hubbell et al. (1999) is to divide the observed species richness by the number of stems. This approach is flawed because (unless the species pool is infinite) the relationship between species richness and number of stems is decidedly nonlinear. Under the null hypothesis that individuals are randomly selected from a common species pool, the species per stem ratio will decline nonlinearly as density increases.

In this paper, instead of 'correcting for' the rarefaction effect, we propose to compare the observed patterns of species richness to a null model in which density is held identical to observed density. In particular, we test whether species richness of $100 \mathrm{~m}^{2}$ plots in a Costa Rican old growth forest is higher than random expectation. If so, we can conclude that the mechanisms that allow the coexistence of rainforest trees operate at very fine scales, and that richness does not merely result from a random draw from a 'species pool'. Alternatively, if richness is lower than random expectation, we can conclude that conspecific trees tend to be aggregated.

\section{Study site}

We conducted this study in the old growth portion of La Selva Biological Station in northeastern Costa Rica. A general review of the facilities, location, geography and climate are presented in Matlock and Hartshorn (1999); see McDade et al. (1994) for a more detailed description. Although there are ca. 400 tree species (including palms) in the 1536-ha property, this number is not exceptionally high for the neotropics (Gentry 1988, Dallmeier and Comiskey 1998, Leigh 1999).

\section{Field methods}

This study employed 1170 circular plots of size $100 \mathrm{~m}^{2}$, located in the old-growth portion of La Selva Biological Station. These plots were located along a grid described in detail in Clark et al. (1998) and Clark et al. (1999). All trees of at least $10 \mathrm{~cm}$ in diameter within each plot were enumerated, by species. Soils for each plot were classified into five classes (Old Alluvium, Recent Alluvium, Residual Soils, Stream Valleys, Swamp Soils) based on texture, color, and landscape position. Topography was classified into four classes (ridge top or flat, top of slope, midslope, and base of slope/riparian). Residual soils constituted the most common soil type, and midslopes the most common topographic class. The proportions of topographic classes varied by soil type (Table 1). Further details on these classifications and methodology are available in Clark et al. (1998), Clark et al. (1999), and Clark and Clark (in press).

\section{Analysis}

Null models

In order to test whether species richness of $100 \mathrm{~m}^{2}$ plots was greater or less than random expectation, we developed randomization tests based on null models of independent assignment of species to individuals. Null models are useful in cases such as this one, where we wish to separate pattern from artifact, and when inferential statistics are unclear, not available, or undefined (Manly 1992). Since the rarefaction effect influences species 
richness in a potentially confounding way, the key is to keep the numbers of individuals per plot the same in the randomizations as in reality. This is so that we are always comparing the same number of trees. In the randomizations, we randomized species identity - but kept the same total number of individuals of each species in the entire study site, and kept the same number of stems in each plot. These randomizations were similar to those performed by Capone and Kushlan (1991). We performed 1000 permutations for each model, and tested whether the mean $o b$ served species richness differed from the mean of the permutations. Since we were interested in deviations in either direction (richness greater than expected, and richness less than expected), we performed a 2-tailed test. For example, at the nominal alpha of 0.05 , we rejected the null hypothesis if the observed value is less than $2.5 \%$, OR greater than $97.5 \%$ of the random values.

We developed three null models. Null Model I was the simplest model, in which we randomized the identity of all species, independent of plot. However, it is possible that since soil types differed from each other in species composition (Clark et al. 1999), species richness per plot would be less than what we would expect due to a random reassignment of species. Therefore, Null Model II also randomized species identities, but only within plots of the same soil type. Although much less important than soil type, topography influenced tree distribution (Clark et al 1999). Null Model III also randomized within soil types AND topographic classes.

For each null model, we tested the overall mean richness, as well as richness within each soil class and each topographic category. Therefore, there were a very large number of statistical tests - so many tests that procedures to correct for multiple comparisons (e.g., Holm's method, Bonferroni adjustment; Legendre and Legendre 1998) would not yield significance even if the effects were strong. Therefore, for each null model, we distinguished between 'exploratory' tests (the tests of the individual soil types and topographic classes), and 'summary' tests (the overall means). We performed multiple comparisons procedures only on the latter, while we treated the former as suggestive and exploratory.

\section{Effects of soil type and topography on species richness}

We were interested in testing whether soil type and topography explain fine-scale variation in species richness, above and beyond the rarefaction effect. We suspected that the rarefaction effect might cause richness differences in this study, because topography and soil type influence stem density at La Selva (Clark and Clark in press). We could not use a straightforward ANCOVA to factor out the rarefaction effect, because richness data (at low richness) are far from normally distributed. In particular, richness cannot be less than zero and hence negative residuals are not likely to be symmetrical with positive residuals. Furthermore, variance in species richness is likely to increase as a function of the mean. Therefore, a Poisson distribution typically better describes richness data than a normal distribution (Pausas 1994, Bradstock et al. 1997, Vetaas 1997, Peco et al. 1998), and we employed generalized linear modelling using a Poisson error distribution and a logarithmic link function (Crawley 1993, McCullagh and Nelder 1983). Statistical inference in generalized linear models is derived from the maximum likelihood principle, and is evaluated by the 'deviance', which has an approximate chi-squared distribution. In this study, we tested whether soil type explained deviance that is not explained by tree density, and whether topography explained any of the deviance that is not explained by density and soil type. We omitted plots with fewer than two trees from the generalized linear modeling.

\section{Results}

The density of tree stems ranged from zero to 11, and species richness ranged from zero to 10 (Figure 1a). Both richness and density peaked at 4 per plot. Figure $1 \mathrm{~b}$ demonstrates a strong rarefaction effect: i.e., we found a strong dependence of richness on density. However, figure $1 \mathrm{~b}$ (and the similarities of the curves in figure 1a) shows that mean tree richness was not much less than the maximum possible tree richness (i.e., when each tree in a plot was a different species).

The closeness of tree species richness to the maximum richness implies that it is worthwhile determining whether species richness was higher than random expectation. However, the results of the randomization tests under all null models (Table 2) demonstrated that mean species richness was always lower than random expectation. Although the difference from expectation is very slight (a small fraction of a species), the departures from randomness were, in many cases, significant (under all three null models). Furthermore, all of the summary tests of means were significant.

It remains to be determined whether there was a relationship between species richness and the soil and topographic classes. Figure 2 demonstrates that species richness did indeed vary as a function of these classes, but that this pattern may have been a simple function of density (i.e., the rarefaction effect). Therefore, we were interested in testing whether soil and topography affected the residuals after accounting for density. Generalized linear 
Figure 1. a) Frequency diagram of species richness per plot together with number of stems per plot. b) Mean richness of plots with different numbers of tree stems, plus or minus one standard error. The upper line represents the hypothetical case where each tree belongs to a different species. $\mathbf{a}$

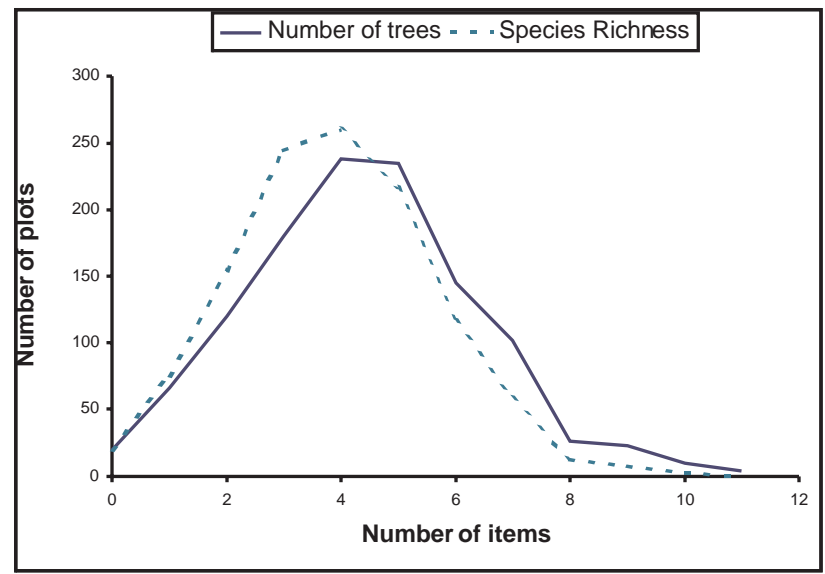

b
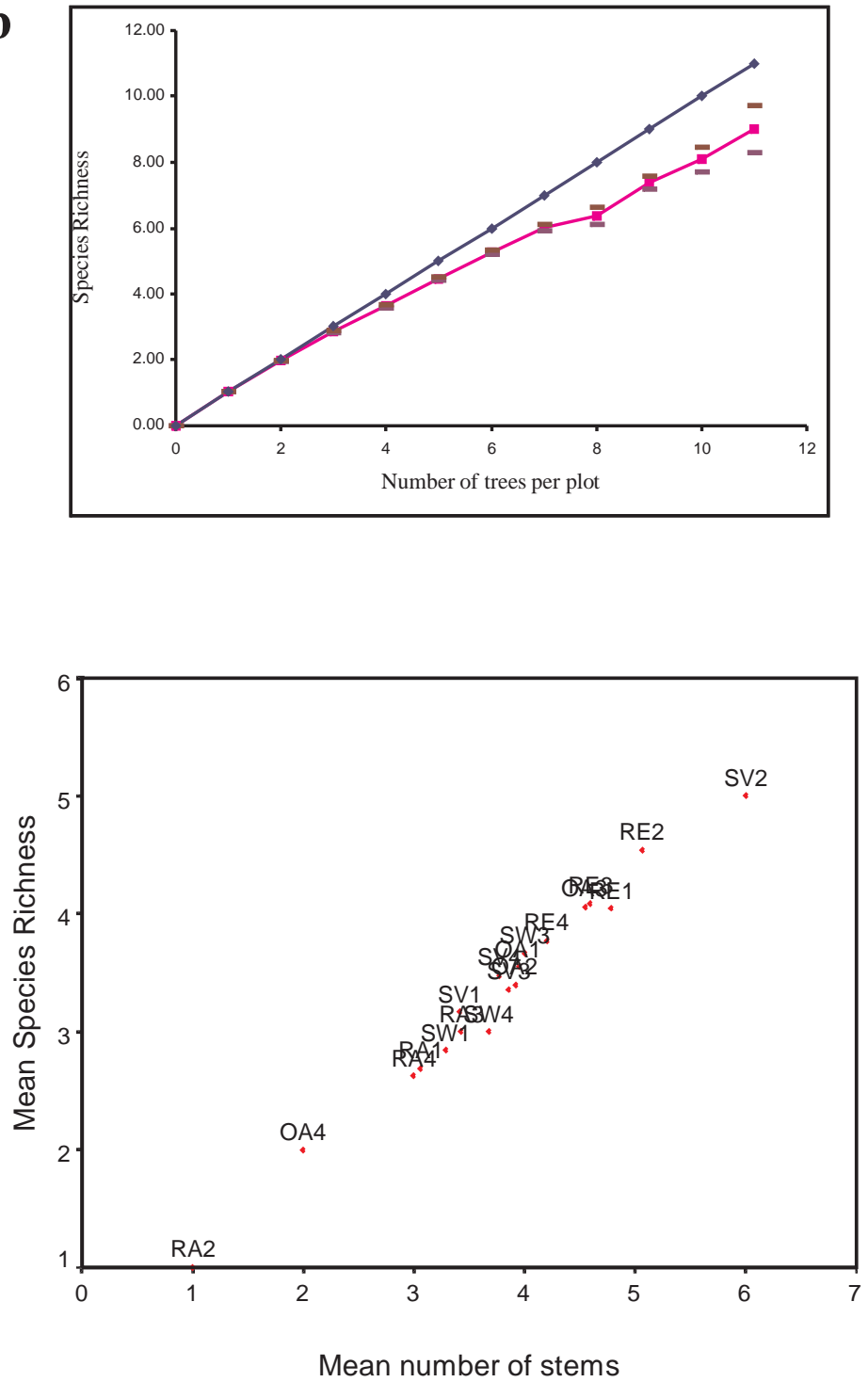

Mean number of stems
Figure 2. Mean species richness as a function of mean stem density, by soil and topographic class. Abbreviations are as in Table 2. The outlying status of RA2, OA4, and SV2 is most likely due to low sample size (Table 1). 
Table 2. Observed mean species richness, as well as average richness of the three null models (NM I, NMII, NMIII) as described in the text. Soil classes OA = Old Alluvium, RA=Recent Alluvium, RE=Residual Soils, SV = Stream Valleys, $\mathrm{SW}=$ Swamp. Topographic categories: $1=$ ridge top or flat, $2=$ top of slope, $3=$ mid slope, $4=$ bottom of slope. Although we performed two-tailed t-tests, the only significant results occurred when observed richness was less than random expectation $(* p<.05, * * p<.01, * * * p<.005, * * * * p<.001)$.

\begin{tabular}{|c|c|c|c|c|c|}
\hline & & TRUE & NM I & NM II & NM III \\
\hline All plots & & 3.895 & 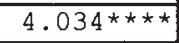 & $4.016^{\star \star \star \star}$ & 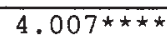 \\
\hline \multirow[t]{5}{*}{ Soil type } & $O A$ & 3.664 & $3.822^{\star \star \star \star}$ & $3.781 \star \star \star$ & $3.776 \star \star \star$ \\
\hline & RA & 2.688 & $2.882^{\star}$ & $2.841^{\star}$ & 2.809 \\
\hline & RE & 4.164 & 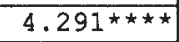 & $4.282^{\star \star \star \star}$ & $4.276^{\star \star \star \star \star}$ \\
\hline & SV & 3.468 & 3.528 & 3.474 & 3.472 \\
\hline & SW & 2.915 & $3.171^{\star \star \star \star \star ~}$ & 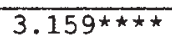 & 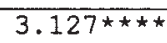 \\
\hline Mean, by soil types & & 3.895 & $4.034^{\star \star \star \star \star}$ & $4.016^{\star \star \star \star}$ & $4.007 \star \star \star \star \star$ \\
\hline \multirow[t]{18}{*}{ Topographic classes } & OA-1 & 3.550 & 3.687 & 3.649 & $3.672^{*}$ \\
\hline & OA-2 & 3.400 & $3.667 \star \star$ & 3.631 * & 3.579 \\
\hline & OA-3 & 4.059 & 4.205 & 4.156 & 4.139 \\
\hline & OA-4 & 2.000 & 1.928 & 1.924 & 1.940 \\
\hline & RA-1 & 2.688 & 2.873 & 2.825 & 2.834 \\
\hline & RA-3 & 3.000 & 3.246 & 3.211 & 3.141 \\
\hline & RA-4 & 2.625 & 2.815 & 2.780 & 2.696 \\
\hline & RE-1 & 4.043 & $4.360^{\star}$ & $4.342^{*}$ & $4.321^{\star \star}$ \\
\hline & RE-2 & 4.541 & 4.625 & 4.615 & 4.597 \\
\hline & RE-3 & 4.087 & $4.224 \star \star \star \star ~$ & $4.215^{\star \star \star \star}$ & $4.216^{\star \star \star \star \star}$ \\
\hline & RE-4 & 3.776 & $3.897^{\star}$ & $3.894^{*}$ & $3.880^{\star}$ \\
\hline & SV-1 & 3.167 & 3.202 & 3.156 & 3.235 \\
\hline & SV-2 & 5.000 & 5.355 & 5.276 & 5.097 \\
\hline & SV-3 & 3.357 & 3.577 & 3.523 & 3.555 \\
\hline & SV-4 & 3.477 & 3.493 & 3.440 & 3.423 \\
\hline & SW-1 & 2.841 & $3.057^{2 \star \star \star \star}$ & $3.050 \star \star \star$ & $3.029 \star \star \star \star$ \\
\hline & SW-3 & 3.667 & 3.754 & 3.730 & 3.543 \\
\hline & SW-4 & 3.000 & $3.350 \star \star \star \star$ & 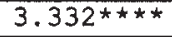 & 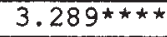 \\
\hline Mean, by topo classes & & 3.895 & $4.034 * \star \star \star$ & $4.016 * \star \star \star$ & $4.007 \star \star \star \star$ \\
\hline
\end{tabular}

modelling (with a Poisson error distribution and a logarithmic link function; Crawley 1993) on species richness revealed a scaled deviance of 635.18 , and a residual degrees of freedom of 1082 . When stem density was added as an explanatory variable, the change in deviance explained was 482.4, which was not surprisingly highly significant $(p<.00001)$. When the soil categories were added to the model, the change in deviance explained was 1.787, which was not significant (4 degrees of freedom). When topography was added, the change in deviance explained was 0.205 , which was also not significant ( 3 d.f.). The behavior of the residuals and the relatively low scaled deviance indicated no problems with overdispersion or heteroscedasticity (Crawley 1993). Therefore, we could detect no soil or topographic effects on fine-scale species richness, after accounting for the effects of density.

\section{Conclusions}

We found that the number of tree species per $100 \mathrm{~m}^{2}$ plot is very close to the maximum possible number. Nevertheless, mean species richness is either indistinguish- able from or significantly lower than random expectation. Thus, we have no evidence that tree species richness is maintained at very fine spatial scales. The fact that perplot richness is so high and yet lower than expectation demonstrates the importance of a large number of available species and the lack of strong dominance (although we do note that the dominance at La Selva is relatively high for tropical forests).

We acknowledge that this study does not directly address mechanisms of 'maintenance'. It merely demonstrates that richness of trees $>10 \mathrm{~cm} \mathrm{DBH}$ at the 0.01 ha scale is no higher than we would expect from a random draw of stems, and that richness is not significantly related to soil types or topographic categories. It is possible that studies incorporating smaller stems, a range of scales, trends through time, or experimentation would yield different answers. Nevertheless, the current results imply that there is no mechanism that elevates richness at the 0.01 ha scale. 
The lower than expected richness means that there are a higher than expected number of conspecifics within a plot. In other words, tree stems are in general slightly aggregated within species. It is not difficult to find plausible explanations for conspecifics to be clumped. For example, it is possible that a clumped distribution is caused by some degree of environmental specificity. However, if soil and topography class are important in determining species composition, the outcome of Null Model III should seldom be significant. It is possible that other unmeasured environmental factors, such as disturbance, cause clumping. Perhaps more likely, the pattern is due to vegetative reproduction and/or limited seed dispersal. A modest degree of clumping is consistent with other studies of tropical tree dispersion (Forman and Hahn 1980, He et al. 1997).

The lack of fine-scale 'maintenance' of species richness does not mean that we can ignore fine-scale explanations for species richness. For example, we cannot dismiss the contributions of seed predators, fungal pathogens, mycorrhizae, and treefall gaps to the diversity of tropical trees. However, we can conclude that it may be difficult to infer the importance of such entities for fine-scale richness patterns if one only studies small plots.

Although the warnings that you need large plots to understand tree species richness (Rosenzweig 1995, Condit et al 1996) have some validity, it is premature to dismiss the utility of small plots for diversity studies. For example, Clark et al. (1999) found, using the same data set as in the present paper, that there were predictable and interpretable relationships between species composition, soil type and topography. Such fine-scale specialization can potentially maintain species richness at the landscape scale, if not the scale of interacting individuals. Therefore, the optimal spatial scale for sampling communities depends on the questions asked (Kenkel et al. 1989, Peterson and Parker 1998).

Acknowledgments: We thank the Andrew W. Mellon Foundation for financial support and the Organization for Tropical Studies for support in the field. J. Bastow Wilson, M. Henry H. Stevens, János Podani, and an anonymous reviewer provided useful criticisms of the manuscript. MWP thanks the José María Fernández-Palacios of the Departamento de Ecología for his hospitality and support during a sabbatical leave.

\section{References}

Bradstock, R. A., M. G. Tozer and D. A. Keith. 1997. Effects of high frequency fire on floristic composition and abundance in a fireprone heathland near Sydney. Austral. J. Bot. 45: 641-655.

Brokaw, N. V. L. 1985. Treefalls, regrowth, and community structure in tropical forests. In: S. T. A. Pickett and P. S. White (eds.), Natural Disturbance and Patch Dynamics. Academic Press, Toronto, pp. 53-69.
Brown, J. H. 1988. Species diversity. In: A. A. Myers and P. S. Giller (eds.), Analytical Biogeography. Chapman and Hall, New York, pp. 57-89.

Capone, T. A. and J. A. Kushlan. 1991. Fish community structure in dry-season stream pools. Ecology 72: 983-992.

Clark, D. B. and D. A. Clark. In press. Landscape-scale variation in forest structure and biomass in a tropical rain forest. For. Ecol. Manage.

Clark, D. B., D. A. Clark and J. M. Read. 1998. Edaphic variation and the mesoscale distribution of tree species in a neotropical rain forest. $J$. Ecol. 86:101-112.

Clark, D. B., M. W. Palmer and D. A. Clark. 1999. Edaphic factors and the landscape-scale distributions of tropical rain forest trees. Ecology 80: 2662-2675.

Condit, R., S. P. Hubbell, J. V. LaFrankie, R. Sukumar, N. Manokaran, R. B. Foster and P. S. Ashton. 1996. Species-area and species-individual relationships for tropical trees: a comparison of three 50-ha plots. J. Ecol. 84: 549-562.

Condit, R., R. B. Foster, S. P. Hubbell, R. Sukumar, E. G. Leigh, N Manokaran, S. Loo de Lao, J. F. LaFrankie and P. S. Ashton. 1998. Assessing forest diversity on small plots: calibration using species-individual curves from 50-ha plots. In: F. Dallmeier and J. A. Comiskey (eds.), Forest Biodiversity Research, Monitoring and Modeling. Conceptual Background and Old World Case Studies. Volume 20. UNESCO, Paris, pp. 247-268.

Connell, J. H. 1978. Diversity in tropical rain forests and coral reefs. Science 199:1302-9.

Crawley, M. J. 1993. GLIM for Ecologists. Blackwell Scientific Publications, Oxford

Dallmeier, F. and J. A. Comiskey (eds.) 1998. Man and the Biosphere, 21: Forest biodiversity in North, Central, and South America, and the Caribbean: Research and Monitoring. UNESCO, Paris.

Denslow, J. S. 1995. Disturbance and diversity in tropical rain forests: the density effect. Ecol. Appl. 5: 962-968.

Forman, R. T. T. and D. C. Hahn. 1980. Spatial patterns of trees in a Caribbean semievergreen forest. Ecology 61:1267-1274.

Gentry, A. H. 1988. Changes in plant community diversity and floristic composition on environmental and geographical gradients. Ann. Miss. Bot. Gard. 75: 1-34.

He, F., P. Legendre and J. V. LaFrankie. 1997. Distribution patterns of tree species in a Malaysian tropical rain forest. J. Veg. Sci. 8: 105-114.

Hubbell, S. P., R. B. Foster, S. T. O’Brien, K. E. Harms, R. Condit, B. Wechsler, S. J. Wright and S. Loo de Lao. 1999. Light gap disturbances, recruitment limitation, and tree diversity in a neotropical forest. Science 283: 554-557.

Huston, M. A. 1994. Biological Diversity. Cambridge University Press, Cambridge, England.

Janos, D. P. 1983. Tropical mycorrhizas, nutrient cycles and plant growth. In: S. L. Sutton, T. C. Whitmore and A. C. Chadwick (eds.), Tropical Rain Forest: Ecology and Management. Blackwell Scientific, Oxford, pp. 327-345.

Janzen, D. H. 1970. Herbivores and the number of tree species in tropical forests. Am. Nat. 104: 501-528.

Kenkel, N. C., P. Juhász-Nagy and J. Podani. 1989. On sampling procedures in population and community ecology. Ve getatio 83 : 195-207.

Legendre, P. and L. Legendre. 1998. Numerical Ecology, 2nd English Edition. Elsevier, Amsterdam. 
Leigh, E. G. Jr. 1999. Tropical Forest Ecology: a View from Barro Colorado Island. Oxford University Press, New York.

Manly, B. F. J. 1992. Randomization and Monte Carlo Methods in Biology. Chapman and Hall, New York.

Matlock, R. B. J. and G. S. Hartshorn. 1999. La Selva Biological Station (OTS). Bull. Ecol. Soc. Am. 80: 188-193.

McCullagh, P., and J. A. Nelder. 1983. Generalized Linear Models. Chapman and Hall, London.

McDade, L. A., K. S. Bawa, H. A. Hespenheide and G. S. Hartshorn (eds.) 1994. La Selva: Ecology and Natural History of a Neotropical Rain Forest. University of Chicago Press, Chicago.

Pärtel, M. and M. Zobel. 1999. Small-scale plant species richness in calcareous grasslands determined by the species pool, community age and shoot density. Ecography 22: 153-159.

Palmer, M. W. 1991. Patterns of species richness among North Carolina hardwood forests: tests of two hypotheses. J. Veg. Sci. 2: 361-366.

Palmer, M. W. 1994. Variation in species richness: towards a unification of hypotheses. Folia Geobot. Phytotax. 29: 511-530.

Palmer, M. W. and E. van der Maare1. 1995. Variance in species richness, species association, and niche limitation. Oikos 73: 203213.

Palmer, M. W. and P. S. White. 1994a. On the existence of communities. J. Veg. Sci. 5: 279-282.

Palmer, M. W. and P. S. White. 1994b. Scale dependence and the species-area relationship. Am. Nat. 144: 717-740.
Pausas, J. G. 1994. Species richness patterns in the understorey of Pyrenean Pinus sylvestris forest. J. Veg. Sci. 5: 517-524.

Peco, B., T. Espigares and C. Levassor. 1998. Trends and fluctuations in species abundance and richness in Mediterranean annual pastures. Appl. Veg. Sci. 1: 21-28.

Peterson, D. L. and V. T. Parker (eds.) 1998. Ecological Scale: Theory and Applications. Columbia University Press, New York.

Rohde, K. 1997. The larger area of the tropics does not explain latitudinal gradients in species diversity. Oikos 79: 169-172.

Rosenzweig, M. L. 1995. Species Diversity in Sspace and Time. Cambridge University Press, Cambridge.

Stevens, G. C. 1989. The latitudinal gradient in geographical range: how so many species coexist in the tropics. Am. Nat. 133: 240256.

Vetaas, O. R. 1997. The effect of canopy disturbance on species richness in a central Himalayan oak forest. Plant Ecol. 132: 29-38.

Wilson, E. O. (ed.). 1998. Biodiversity. National Academy Press, Washington, DC.

Wright, D. H., D. J. Currie and B. A. Maurer. 1993. Energy supply and patterns of species richness on local and regional scales. In: R. E. Ricklefs and D. Schluter (eds.), Species Diversity in Ecological Communities. Historical and Geographical Perspectives. University of Chicago Press, Chicago, pp. 66-74 